Preprint September 2021: please cite published version

Drayson. Z. (forthcoming) 'What we talk about when we talk about mental states' in Tamas Demeter, Ted Parent and Adam Toon (eds.), Mental Fictionalism: Philosophical Explorations. Routledge.

\title{
What we talk about when we talk about mental states ${ }^{1}$
}

\section{Zoe Drayson}

University of California, Davis

Fictionalists propose that some apparently fact-stating discourses do not aim to convey factual information about the world, but rather allow us to engage in a fiction or pretense without incurring ontological commitments. Some philosophers have suggested that using mathematical, modal, or moral discourse, for example, need not commit us to the existence of mathematical objects, possible worlds, or moral facts. The mental fictionalist applies this reasoning to our mental discourse, suggesting that we can use 'belief' and 'desire' talk without committing to the existence of beliefs and desires as mental entities. Most arguments for mental fictionalism are based on two key suppositions: first, that there are ontological concerns about mental entities; and second, that these ontological concerns justify a fictionalist interpretation of mental discourse. This paper challenges both suppositions and argues that the standard arguments for mental fictionalism are substantially weaker than arguments for other forms of fictionalism in the philosophical literature.

Keywords: realism, eliminativism, fictionalism, propositional attitudes

\section{Introduction}

When I tell my neighbour, "Your cat is on my porch", you can probably assume that I am aiming to convey factual information about the objective world, and that I am committed to the

\footnotetext{
${ }^{1}$ The title is inspired by that of Raymond Carver's (1981) short story, 'What we talk about when we talk about love', from the collection of the same name.
} 
Preprint September 2021: please cite published version

Drayson. Z. (forthcoming) 'What we talk about when we talk about mental states' in Tamas Demeter, Ted Parent and Adam Toon (eds.), Mental Fictionalism: Philosophical Explorations. Routledge.

existence of my neighbour's cat, my own porch, and a certain spatiotemporal relation between the two. Now consider a situation in which I am playing make-believe with my niece and I tell her, "Your giraffe is on my spaceship". If I had been aiming to convey factual information about the objective world, I would have failed; I do not have a spaceship and she does not have a giraffe. But these are not the aims of a make-believe discourse: I am successfully engaging with a pretense or fiction rather than trying-but-failing to make true claims about the mindindependent world. This suggests that the make-believe discourse should be given a fictionalist interpretation, on which I can talk as if your giraffe is on my spaceship without being ontologically committed to the objective existence of either entity.

Some philosophers claim that mathematical, modal, moral, or mental discourse can (or should) be given a similarly fictionalist interpretation: this would allow us to understand the relevant discourse as valuable or successful even if it failed to convey factual information about the objective world. ${ }^{2}$ In this paper, I argue that the standard arguments for mental fictionalism are significantly weaker than the standard arguments for mathematical, modal and moral fictionalism. Mathematical, modal and moral fictionalists are generally motivated by skepticism or agnosticism about the objective existence of certain entities (e.g. abstract objects, possible worlds, moral facts) and provide further reasons to prefer fictionalism over alternative semantic interpretations of the discourse. I will argue that when we turn to fictionalist interpretations of mental discourse, the ontological concerns about propositional attitudes are harder to motivate than ontological concerns about mathematical, modal, or moral entities. To the extent that such ontological concerns could motivate a particular semantic interpretation of mental discourse, it is also unclear why this should be a fictionalist interpretation.

\footnotetext{
${ }^{2}$ Fictionalism comes in two varieties, hermeneutic and revolutionary. Hermeneutic fictionalism claims that we are fictionalists about a discourse; revolutionary fictionalists claim that we ought to be fictionalists about a discourse. Most mental fictionalists are hermeneutic fictionalists, so that will be the focus of my arguments here.
} 
Preprint September 2021: please cite published version

Drayson. Z. (forthcoming) 'What we talk about when we talk about mental states' in Tamas Demeter, Ted Parent and Adam Toon (eds.), Mental Fictionalism: Philosophical Explorations. Routledge.

I will first introduce the key ideas behind fictionalism in general (Section 2) and summarise some of the claims made by mental fictionalists (Section 3). I then raise serious challenges to the mental fictionalist's ontological concerns (Section 4), and to their preference for fictionalism over alternative semantic interpretations (Section 5). I will conclude by exploring alternative routes to mental fictionalism, such as appealing to non-ontological motivations (Section 6).

\section{Fictionalism about a discourse}

The default interpretation of much of our everyday talk is realist, in the sense that it ontologically commits us to the entities we posit. This ontological commitment results from two apparent features of the discourse. First, the sentences of our everyday discourse have a truth-conditional semantics: they purport to represent the world by expressing propositions that can be evaluated as true or false according to how the world is. Second, our utterances of sentences assert the truth of the propositions expressed; to accept a sentence of the discourse is to believe it to be true. $^{3}$

There are thus two ways to deny that a discourse is ontologically committing. One might claim that the discourse does not have a truth-conditional semantics, as the expressivist about ethical discourse does - thus rejecting the first assumption. Or one might allow that the discourse has a truth-conditional semantics but deny that accepting its sentences amounts to believing in their truth, as the constructive empiricist about scientific discourse does - thus rejecting the second assumption. A fictionalist interpretation of a discourse has more in common with the constructive empiricist than with the expressivist. The fictionalist proposes both that the sentences of a particular discourse purport to express truth-evaluable propositions but that

\footnotetext{
${ }^{3}$ In taking realism about a discourse to have both semantic and metaphysical components, I am following Wright (1995), Kalderon (2005), and Kroon (2011).
} 
Preprint September 2021: please cite published version

Drayson. Z. (forthcoming) 'What we talk about when we talk about mental states' in Tamas Demeter, Ted Parent and Adam Toon (eds.), Mental Fictionalism: Philosophical Explorations. Routledge.

utterances of these sentences do not have their normal assertoric force. ${ }^{4}$ As a result, the discourse fails to be ontologically committing in the usual way, and thus does not convey factual information about the objective world.

Fictionalists propose that a discourse which does not convey true claims about the mindindependent world can nonetheless be achieving something important. Fictionalists claim that some truth-evaluable discourses can be valued for properties other than their truth: such discourses have "non-epistemic virtues" (Demeter 2013, p. 497); their propositions are "somehow good or interesting or useful independently of their truth value" (Kalderon 2005, p. 108). Fictionalism about a discourse thus claims that "utterances of sentences of the discourse are best seen not as efforts to say what is literally true, but as useful fictions of some sort" (Eklund 2019).

Fictionalists tend to be motivated by ontological concerns - although I'll consider an alternative motivation in Section 6. They usually want to avoid an ontologically-committing discourse because they have reason to think that the accompanying ontology would be problematic:

"Fictionalism about a discourse $D$ is often seen as attractive precisely because it promises to get around otherwise potentially serious philosophical problems regarding $D$ 's ontology." (Eklund 2019)

"The most common motivation for the development of a philosophical fictionalist account is ontological, specifically, avoiding putatively problematic ontological commitment." (Woodbridge and Armour Garb 2015, p. 12) ${ }^{5}$

\footnotetext{
${ }^{4}$ Fictionalists have various different ways to account for lack of assertoric force: they can appeal to prefixes or prefaces, or propose that we engage in 'quasi-assertion'. When applied to mathematical, modal, or moral discourse, hermeneutic fictionalism faces the "phenomenological objection": it doesn't seem to us as if we are engaging in make-believe when we use the discourse in question. (See Eklund 2019 for further discussion). Mental fictionalism presumably faces a similar phenomenological objection.

${ }^{5}$ I take ontological concerns to be motivations for fictionalism rather than prerequisites: fictionalism is a semantic claim involving ontological agnosticism about a discourse, rather than outright rejection of the ontology. In doing so, I follow Woodbridge and Armour-Garb, who caution against "[c]onfusing this motivation for 'going fictionalist' with the definitive feature of fictionalism" (Woodbridge and Armour Garb 2015, p. 12).
} 
Preprint September 2021: please cite published version

Drayson. Z. (forthcoming) 'What we talk about when we talk about mental states' in Tamas Demeter, Ted Parent and Adam Toon (eds.), Mental Fictionalism: Philosophical Explorations. Routledge.

As the following examples show, standard arguments for fictionalism about mathematical, modal and moral discourse involve a two-step process: they raise concerns about the discourse's ontology, and then argue that a fictionalist interpretation of the discourse is the best way to alleviate these concerns.

First, consider mathematical discourse. On a realist interpretation, mathematical discourse is ontologically committed to the existence of mathematical objects, usually in their platonic form as abstract objects. This raises two concerns: how can there be objects which lack spatiotemporal properties, and how could we cognitively access objects with no causal properties? There are several semantic interpretations of the mathematical discourse which could reject the ontological commitment, but fictionalism does so while allowing us to retain the benefits of a truth-evaluable discourse, such as the ability to draw inferences from some mathematical sentences to others. ${ }^{6}$ Second, consider modal discourse about possible worlds: if this comes with an ontological commitment to countless concrete worlds like our own, then we are faced with a very revisionary ontology. ${ }^{7}$ If the modal realist commits instead to ersatz worlds (abstract representations of possible worlds), then concerns about abstract objects arise similar to the mathematical case. The advantage of fictionalism is that "you can believe everything the fictionalist says about the truth conditions for modal statements without having to believe in possibilia" (Rosen 1990, p. 338). As a third example, consider moral discourse. A realist interpretation of our utterances concerning what is right or wrong is ontologically committed to the existence of moral facts, raising questions about what sorts of entities these are, and why we disagree so much about them. ${ }^{8}$ While there are several semantic interpretations of moral discourse which reject these ontological commitments, the fictionalist interpretation does so while allowing that our moral

\footnotetext{
${ }^{6}$ See Balaguer (2018) for further discussion of the alternative semantic interpretations.

${ }^{7}$ Even Lewis, the main proponent of such a view, acknowledges that his theory of possible worlds "does disagree, to an extreme extent, with firm common sense opinion about what there is" (Lewis 1986, p. 133).

${ }^{8}$ These two questions correspond respectively to Mackie's (1977) arguments from 'queerness' and relativity.
} 
Preprint September 2021: please cite published version

Drayson. Z. (forthcoming) 'What we talk about when we talk about mental states' in Tamas Demeter, Ted Parent and Adam Toon (eds.), Mental Fictionalism: Philosophical Explorations. Routledge.

discourse has values beyond its truth: truth-evaluable talk of rules and obligations might help to motivate us toward moral behavior even if there are no corresponding entities. ${ }^{9}$

In each of these cases above, there is a worry that the entities in question - mathematical objects, possible worlds, moral facts - do not exist. Either we accept that the discourse in question is massively in error, or we adopt a semantic interpretation of the discourse according to which it is not in fact ontologically committing. (I'll consider the error-theoretic option in Section 5.) Some rejections of ontological commitment involve rejecting that the discourse has a truth-evaluable semantics. If it is important to maintain the truth-evaluability of the discourse, fictionalism can permit this without saddling us with the problematic ontology. I propose, however, that mental fictionalism is significantly less well-motivated than mathematical, modal, or moral fictionalism. Proponents of mental fictionalism have not demonstrated similar concerns about mental entities or shown why fictionalism is preferable to other semantic interpretations of mental discourse. Before making this argument, however, I will introduce mental fictionalism in more detail.

\section{Mental fictionalism}

This paper focuses on fictionalist interpretations of mental discourse, also known as mental fictionalism. In this section I will consider how we should characterize mental fictionalism, then I will explore its motivations. ${ }^{10}$ The term 'mental discourse', considered broadly, could encompass a wide variety of mental state ascriptions involving sensations, emotions, mental imagery, and moods. I will follow the practice of most mental fictionalists, however, and focus

\footnotetext{
9 Joyce, for example, argues that moral discourse functions "to bolster self-control against practical irrationality" (Joyce 2005, p. 301) and can perform this role even if there are no moral facts.

${ }^{10}$ Much of the discussion around mental fictionalism has focused on whether or not it is self-defeating, leading to cognitive collapse (Parent 2013, Wallace 2016). In this paper I will assume that mental fictionalism is a coherent position, and I will focus on showing that it lacks motivation and justification.
} 
Preprint September 2021: please cite published version

Drayson. Z. (forthcoming) 'What we talk about when we talk about mental states' in Tamas Demeter, Ted Parent and Adam Toon (eds.), Mental Fictionalism: Philosophical Explorations. Routledge.

in this paper on our everyday practise of ascribing 'folk psychological' propositional attitudes (e.g., beliefs, desires) to people.

On a realist interpretation of our mental discourse, our sentences ascribing psychological predicates express truth-evaluable propositions, and we assert the truth of these propositions when we utter the sentences in question, thus committing to the existence of mental entities. Mental fictionalists accept the realist's assumption that mental discourse is truth-evaluable, but propose that we can utter or accept its sentences without genuinely asserting or believing the propositions they express. The result is that we can keep the mental discourse "as of" mental entities but without incurring ontological commitments to these entities. Fictionalists assume that there is a benefit to keeping the discourse: that "even if mental states do not exist, it is useful to talk as if they do" (Toon 2016, p. 280); that "[w]e should (or do) treat folk psychology as a useful fiction-false, but valuable" (Wallace 2016, p. 405); or that even if sentences of mental discourse are not true of the objective world, they "can be true in a fiction relative sense" (Parent 2013, p. 607).

It is widely acknowledged that " $[\mathrm{t}]$ he most familiar motivation for [mental] fictionalism is a worry about ontological commitment" (Toon 2016, p. 284, see also Wallace 2007) which gives us reason to avoid committing to the existence of mental entities or properties over which our mental discourse quantifies. Opinions differ as to the strength of the ontological concern: Parent characterizes the fictionalist as motivated explicitly by the claim that "[ $\mathrm{t}]$ he mental states posited by folk psychology do not exist" (Parent 2013, p. 606, my italics), while Wallace allows that the mental fictionalist "is at heart a mental eliminativist, or mental agnostic" (Wallace 2016, p. 407, my italics). In the following section, I'll argue that the most commonly-voiced ontological concerns about propositional attitudes do not motivate mental fictionalism to the same extent that concerns about the existence of mathematical objects, possible worlds, and moral facts motivate mathematical, modal, and moral fictionalism. 
Preprint September 2021: please cite published version

Drayson. Z. (forthcoming) 'What we talk about when we talk about mental states' in Tamas Demeter, Ted Parent and Adam Toon (eds.), Mental Fictionalism: Philosophical Explorations. Routledge.

\section{The ontology of mental entities}

A realist interpretation of mental discourse takes our ascriptions of psychological predicates to be ontologically committing. Where the mental discourse is folk psychology, the entities in question are propositional attitudes: mental states in which a subject takes a particular psychological stance or attitude (e.g., believing, desiring) to a truth-evaluable state of affairs indicated by a 'that'-clause (that Gary Oldman is 13 days younger than Gary Numan, for example, or that the fictional place names in Indiana Jones and the Temple of Doom are taken from Paul Scott's Raj Quartet series of novels). ${ }^{11}$

Whether we should be agnostic or even skeptical about the existence of propositional attitudes depends on what sorts of mental states we take propositional attitudes to be. Is a propositional attitude a non-relational property of a person, a two-place relation between a person and a proposition, or a three-place relation in which the person is related to an intermediary representation of a proposition? Are the relations in question causal or dispositional? Is being interpretable as possessing a certain propositional attitude necessary and sufficient for possessing the propositional attitude? ${ }^{12}$ Depending on the nature of propositional attitudes, a realist interpretation of mental discourse might be committed to the existence of functional roles, representations, dispositions, interpretations, or a combination thereof.

\footnotetext{
${ }^{11}$ I leave it open whether these truth-evaluable states of affairs should be understood as abstract propositions or concrete sentences.

12 See Schwitzgebel (2019) for the various ways to understand the metaphysical nature of propositional attitudes.
} 
Preprint September 2021: please cite published version

Drayson. Z. (forthcoming) 'What we talk about when we talk about mental states' in Tamas Demeter, Ted Parent and Adam Toon (eds.), Mental Fictionalism: Philosophical Explorations. Routledge.

Notice that instantiating a propositional attitude is not necessarily a matter of tokening an internal particular. ${ }^{13}$ Fodor's (1987) proposal, that a realist interpretation of folk psychological discourse is best served by reducing propositional attitudes to physically-implemented computational states with syntactic and semantic structure, is only one of many positions in the metaphysics of mind. Mental fictionalists like Toon, however, suggest that their ontological motivations come from "various arguments for eliminativism about mental states (e.g. Churchland 1981, Ramsey, Stich and Garon 1990)" (Toon 2016, p. 284) which are targeted specifically at propositional attitudes insofar as they are internal computational states. These well-known arguments for eliminativism claim that on our best understanding of cognitive architecture, computational neural states do not have the properties required by Fodor's account: some propose that neural properties (e.g. action potentials, spreading activation, spiking frequencies) lack the appropriate syntactic structure; others propose that even syntacticallystructured neural states would lack the semantic properties required to individuate them as propositional attitudes. ${ }^{14}$ Demeter's (2013) mental fictionalism is similarly motivated by the concern that " $[\mathrm{t}]$ he logical interconnections among propositional attitudes [...] have no analogy among the constituents of the physical world" (Demeter 2013, p. 487). If his claim is true, it raises ontological concerns about propositional attitudes only if we suppose that their logical transformations must be reducible to physical interactions; this is just to assume a Fodor-style view of propositional attitudes as certain kinds of computational states. To the extent that any of these eliminativist arguments raise concerns about the ontological status of propositional attitudes, they do so only for a very particular metaphysics of mental states. Mathematical, modal, and moral fictionalists are much clearer about what kinds of entities they take to be problematic and why. (In Section 6, I will consider whether there are other varieties of eliminativism which would better motivate the mental fictionalist.)

\footnotetext{
${ }^{13}$ Williamson, following Steward (1997), emphasises that "[s]ubjects are in mental states, not vice versa" (Williamson 2009, p. 331).

${ }^{14}$ Churchland (1986) is a clear example of the syntactic claim in question, while Stich (1983) explicitly makes the semantic claim.
} 
Preprint September 2021: please cite published version

Drayson. Z. (forthcoming) 'What we talk about when we talk about mental states' in Tamas Demeter, Ted Parent and Adam Toon (eds.), Mental Fictionalism: Philosophical Explorations. Routledge.

Even if there were no such entities as propositional attitudes, this would merely suggest that our mental discourse is systematically in error: that sentences ascribing psychological predicates are either false or lacking a truth value. This alone would not motivate an ontologically noncommitting interpretation of the discourse: perhaps our mental discourse is simply in error. Further argument is required to take us from ontological concerns about propositional attitudes to any semantic reinterpretation of the discourse, fictionalist or otherwise. ${ }^{15}$

\section{The semantics of mental discourse}

Whatever conclusions we reach about the ontological status of mental entities, there is still a further question about how to understand the content, purpose and legitimacy of our psychological discourse (Wright 1995). I have suggested that the standard arguments for mental fictionalism are under-motivated by the eliminativist arguments on which they seem to rely. But even if we have reason to question the existence of propositional attitudes, this seems to entail at most an error-theoretic understanding of mental discourse. Given the possibility of an error theory, there are two available strategies: we can either acknowledge the error and adjust the discourse accordingly, or we can deny that the discourse makes the ontological commitments that would result in the error. In the face of error-theory, the fictionalist makes two moves: they adopt the second of these strategies, and then argue that fictionalism is the best semantic interpretation of the discourse for avoiding ontological commitment. In the literature on mental fictionalism, however, neither of these two moves is explicitly justified. ${ }^{16}$

\footnotetext{
${ }^{15}$ Ramsey (2021) acknowledges that there are various ways in which different versions of fictionalism and antirealism can agree with and pull apart from eliminativism, and that it would an interesting and valuable project to explore these. I consider this paper to be a first step in that direction.

${ }^{16}$ Many of the eliminativists discussed in the previous section make a similarly unjustified move toward the first of the two strategies: they assume that if the discourse is systematically in error, it should be rejected or replaced (perhaps by a non-mental description of neural processing) rather than given a different semantic interpretation. The tendency to assume that the elimination of entities entails the elimination of the discourse is so common that many of the classic statements of eliminativism conflate the two positions (Joyce 2013).
} 
Preprint September 2021: please cite published version

Drayson. Z. (forthcoming) 'What we talk about when we talk about mental states' in Tamas Demeter, Ted Parent and Adam Toon (eds.), Mental Fictionalism: Philosophical Explorations. Routledge.

Consider the fictionalist's first move, from error-theory to the denial of ontological commitment. Why not accept that our ontologically committing discourse simply fails to refer, and adjust (or even replace) the discourse accordingly? This, as Ramsey (2021) points out, is what we have done with talk of celestial spheres, demons, and caloric fluid. Some varieties of fictionalism seem justified in rejecting the discourse-adjustment strategy, because there particularly strong reasons to think that certain discourses cannot be revised. Faced with ontological concerns about mathematical objects, for example, it would be odd to suggest that we should revise the seemingly tautological and a-priori-knowable claims of mathematics (e.g. ' $2+2=4$ ', ' 7 is a prime number'). Doubts about mathematical objects seem more likely to motivate an alternative semantic interpretation of the discourse rather than a revision or rejection of the discourse. The mental fictionalist, however, can only follow the mathematical fictionalist in this respect if they assume that we have similarly a priori access to the truth of sentences in our mental discourse. ${ }^{17}$ On such an assumption, however, many of the standard forms of eliminativism about propositional attitudes are a lot less persuasive because they rely on the assumption that cognitive science has made empirical discoveries about our neural architecture which can alter the truth of sentences in our mental discourse. ${ }^{18}$

Let us allow that the mental fictionalist could be justified in considering an alternative semantic interpretation of the mental discourse, on which there is no ontological commitment to propositional attitudes. The fictionalist must now make their second move, justifying a fictionalist interpretation of the discourse over other semantic approaches which would also

\footnotetext{
17 Some philosophers of mind argue that it is incoherent to question the existence of mental entities, due to the firstperson knowledge we have of our mental states. Wright proposes that "ordinary psychology has a kind of diplomatic immunity in realist vs antirealist debate" (Wright 1995, p. 230) because we do not have a cogent or even coherent grasp of what it would be to deny mental ontology. Marton and Tozser (2013) suggest that we cannot question the existence of mental entities on the grounds that only conscious experiences are genuinely mental and that we cannot be sceptical of conscious experience. This leads them to argue, as I do, that mental fiction is undermotivated, although for very different reasons.

18 As Ramsey (2021) demonstrates, some positions described in the literature as 'eliminativist' are not actually raising doubts about the existence of the posited entities: they are instead questioning how we ought to categorize or classify the entities in question. Ramsey proposes that such a position involves kind-dissolution rather than eliminativism.
} 
Preprint September 2021: please cite published version

Drayson. Z. (forthcoming) 'What we talk about when we talk about mental states' in Tamas Demeter, Ted Parent and Adam Toon (eds.), Mental Fictionalism: Philosophical Explorations. Routledge.

reject the ontological commitments - such as expressivism or deflationism. An expressivist interpretation of a discourse denies ontological commitment by proposing that the discourse is not even truth-evaluable: perhaps our mental discourse expresses emotions instead of representing facts about propositional attitudes. A deflationary interpretation of a discourse denies substantial ontological commitment to objective entities by understanding the discourse as only minimally truth-evaluable, where truth does not require correspondence to substantial worldly facts. A deflationary interpretation of mental discourse could allow that folk psychology is truth-apt while denying that this commits it to the existence of mental entities as such.

In the philosophical literature on fictionalism more generally, these alternative semantic interpretations are acknowledged and evaluated alongside the fictionalist proposal. Mathematical fictionalists, for example, provide arguments for preferring mathematical fictionalism to paraphrase nominalism and deflationary-truth nominalism (Balaguer 2018); while moral fictionalists provide arguments for preferring moral fictionalism to projectivism and quasirealism (Nolan, Restall, and West 2005). Mental fictionalists, however, seem to assume not only that rejecting ontological commitment is preferable to embracing error theory, but also that fictionalism is the default semantic interpretation for those seeking to avoid ontological commitment.

I have not been arguing against mental fictionalism per se, but rather against the way that mental fictionalists have tended to motivate and argue for the position in the literature. In the following section, I'll explore how mental fictionalists might develop their position in order to avoid these criticisms.

\section{Strengthening the case for mental fictionalism?}

Mental fictionalists, I have argued, seem to be largely motivated by ontological concerns about the existence of propositional attitudes. If they want to continue relying on such ontological 
Preprint September 2021: please cite published version

Drayson. Z. (forthcoming) 'What we talk about when we talk about mental states' in Tamas Demeter, Ted Parent and Adam Toon (eds.), Mental Fictionalism: Philosophical Explorations. Routledge.

motivations, they need to demonstrate that the ontologically suspect entities are the same entities to which the discourse seems ontologically committed. An eliminativist argument which purports to show that there are no computational neural states with the appropriate syntactic and semantic properties does not demonstrate that there are no propositional attitudes, unless accompanied by further justification for thinking that propositional attitudes must be reducible to such computational states.

One option for the mental fictionalist, therefore, would be to argue that there are no propositional attitudes tout court, regardless of how we understand the metaphysics of mind. If there are no abstract propositions or concrete sentences, for example, then there can be no mental states which require relations to such entities. ${ }^{19}$ (Notice, however, that this would still allow for Kriegel's (2011) monadic view of propositional attitudes, on which propositional content is an intrinsic property of the mental state.)

A second option for the mental fictionalist would be to shift their focus from folk-psychological discourse which posits propositional attitudes to the scientific discourse of computational psychology which posits physically-implemented vehicles of representation. If the scientific discourse was committed to the existence of syntactically and semantically structured computational states, then the standard eliminativist arguments might be more persuasive. There is already a literature on fictionalism about neural representations (see Sprevak 2013, Ramsey $\mathrm{ms}$ ), but its conclusions are not directly relevant to the sorts of claims about folk psychological fictionalism that Toon and Demeter, for example, are interested in.

A third option for the mental fictionalist would be to replace or supplement the ontological motivation for fictionalism with different motivating factors. Some fictionalists accept the possibility of such an approach but acknowledge that it is unusual and hard to motivate (Joyce 2013). Others are more optimistic: Yablo (2001) proposes that the best arguments for

\footnotetext{
${ }^{19}$ Wallace (2016) considers this as a possible motivation for mental fictionalism, but I know of nobody in the literature who takes this approach.
} 
Preprint September 2021: please cite published version

Drayson. Z. (forthcoming) 'What we talk about when we talk about mental states'
in Tamas Demeter, Ted Parent and Adam Toon (eds.),
Mental Fictionalism: Philosophical Explorations. Routledge.

fictionalism focus on the discourse itself, rather than on its relation to the world. He suggests that the standard ontological arguments for fictionalism are unworkable, given how difficult it is to establish the non-existence of the entities in question. Instead, we should focus on the features of a discourse which suggest a fictionalist interpretation is preferable:

"[T] here is another possible rationale for fictionalism. Just maybe, it gives the most plausible account of the practice. It is not that X's are intolerable, but that when we examine X-language in a calm and unprejudiced way, it turns out to have a whole lot in common with language that is fictional on its face." (Yablo 2001, p. 87) ${ }^{20}$

Whether the mental fictionalist is motivated by ontological concerns or the features and practise of the discourse, they still need to show why fictionalism is preferable to alternative semantic interpretations such as expressivism or deflationism about mental discourse. ${ }^{21}$ Here, the mental fictionalist could draw on analogies with other varieties of fictionalism: mathematical fictionalists, for example, argue specifically that their position does a better job of accounting for the indeterminacy, representationality, necessity and a prioricity of mathematical discourse than alternative semantic interpretations (Yablo 2001). ${ }^{22}$ It is far from clear, however, that the benefits of fictionalism about mathematical, modal, and moral discourse will extend to fictionalism about mental discourse. Wright (1995) suggests that once we start focusing on mental discourse rather than mental entities, the indeterminacy of psychological interpretation is more likely to push us toward expressivism than fictionalism about mental discourse; Thomasson (2013) argues that

${ }^{20}$ Toon considers this approach as an option for mental fictionalists:

"Rather than being persuaded by arguments for eliminativism, the fictionalist might primarily be interested in making sense of our ordinary talk about the mind. When we examine such talk closely, she might argue, we find that it is best understood in fictionalist terms: despite appearances to the contrary, in fact the folk are not committed to the existence of beliefs and desires" (Toon 2016, p. 284).

Wallace (2016) also acknowledges that mental fictionalism need not require eliminativism or even agnosticism about mental entities.

${ }^{21}$ Notice that Demeter's (2013) argument for mental fictionalism doesn't even distinguish it from forms of expressivism: if anything, it seems to give a hybrid account of mental discourse which is both fictionalist and expressivist. He proposes that his view is a form of mental fictionalism on the grounds that it does not aim at truth, but on the grounds that our mental discourse expresses affects rather than reporting facts.

${ }^{22}$ See also Rosen's (1990) arguments for preferring fictionalism about mental discourse, and Nolan, Restall, and West's (2005) arguments for preferring fictionalism about moral discourse. 
Preprint September 2021: please cite published version

Drayson. Z. (forthcoming) 'What we talk about when we talk about mental states' in Tamas Demeter, Ted Parent and Adam Toon (eds.), Mental Fictionalism: Philosophical Explorations. Routledge.

focusing on a discourse rather than an ontology will motivate a deflationary interpretation of the discourse over a fictionalist interpretation.

\section{Conclusion}

Fictionalism is a semantic interpretation of a discourse, which is often motivated by ontological concerns. Philosophers have argued for fictionalist interpretations of our mathematical discourse, our modal discourse, and our moral discourse. These arguments attempt to motivate fictionalism by highlighting genuine ontological worries about the relevant entities, showing why error theory is incompatible with certain properties of the discourse, and providing reasons to prefer fictionalism over alternative semantic interpretations which also lack ontological commitments.

Proponents of mental fictionalism suggest that their position is analogous to mathematical, modal, and moral fictionalisms. We would therefore expect the mental fictionalist to follow a similar strategy: justifying ontological concerns about mental entities; showing why an error theory of mental discourse should be rejected rather than accepted; and presenting the benefits that fictionalist interpretations of mental discourse provide over other ontologically noncommitting semantic interpretations. I have argued in this paper that proponents of mental fictionalism have not succeeded in these areas, and I have concluded that fictionalism about mental discourse is thus undermotivated by comparison to fictionalism about mathematical, modal and moral discourse. My criticisms, however, have focused on the extant mental fictionalism literature rather than on mental fictionalism as a position in logical space. I have thus allowed that there may be different ways to motivate mental fictionalism and stronger arguments to support it, and I have included some positive suggestions for the future development of fictionalist interpretations of mental discourse. 
Preprint September 2021: please cite published version

Drayson. Z. (forthcoming) 'What we talk about when we talk about mental states' in Tamas Demeter, Ted Parent and Adam Toon (eds.), Mental Fictionalism: Philosophical Explorations. Routledge.

\section{Acknowledgments}

This paper was originally presented at a 2019 conference on mental fictionalism in Budapest, organized by Tamás Demeter, Ted Parent, and Adam Toon. Versions have also been presented at the University of California, Irvine; and at the University of Nevada, Las Vegas (where Bill Ramsey and James Woodbridge provided particularly helpful feedback). I am grateful for the opportunity to discuss this paper with my Spring 2021 graduate seminar and the philosophy of mind reading group at UC Davis, and to Sam Wilkinson for his comments. I am particularly indebted to Jordan Bell for his feedback on various versions of this paper.

\section{Bibliography}

Armour-Garb, Bradley \& Woodbridge, James A. (2015) Pretense and Pathology: Philosophical

Fictionalism and its Applications. Cambridge: Cambridge University Press.

Balaguer, Mark. (2018) "Fictionalism in the Philosophy of Mathematics", The Stanford

Encyclopedia of Philosophy (Fall 2018 Edition), Edward N. Zalta (ed.), URL =

$<$ https://plato.stanford.edu/archives/fall2018/entries/fictionalism-mathematics/>.

Carver, Raymond. (1981) What we talk about when we talk about love. Knopf.

Churchland, Patricia Smith. (1986) Neurophilosophy: Toward A Unified Science of the Mind-

Brain. Cambridge, MA: MIT Press.

Demeter, Tamás. (2013) Mental fictionalism: the very idea. The Monist 96 (4):483-504.

Eklund, Matti, "Fictionalism", The Stanford Encyclopedia of Philosophy (Winter 2019 Edition), Edward N. Zalta (ed.), URL =

$<$ https://plato.stanford.edu/archives/win2019/entries/fictionalism/>.

Fodor, Jerry A. (1987). Psychosemantics: The Problem of Meaning in the Philosophy of Mind. Cambridge, MA: MIT Press. 
Preprint September 2021: please cite published version

Drayson. Z. (forthcoming) 'What we talk about when we talk about mental states' in Tamas Demeter, Ted Parent and Adam Toon (eds.), Mental Fictionalism: Philosophical Explorations. Routledge.

Joyce, Richard. (2013) Psychological fictionalism, and the threat of fictionalist Suicide. The Monist 96 (4):517-538.

Kalderon, Mark Eli. (2005) Moral Fictionalism. Oxford: Clarendon Press.

Kriegel, Uriah. (2011) The sources of intentionality. Oxford: Oxford University Press.

Kroon, Frederick. (2011) Fictionalism in metaphysics. Philosophy Compass 6 (11):786-803.

Lewis, David. (1986) On the Plurality of Worlds. Oxford: Wiley-Blackwell.

Mackie, John Leslie (1977). Ethics: Inventing Right and Wrong. London: Penguin Books.

Márton, Miklós \& Tözsér, János (2013). Mental Fictionalism As an Undermotivated Theory. The Monist 96 (4):622-638.

Nolan, D., Restall, G. \& West, C. (2005) Moral fictionalism versus the rest. Australasian Journal of Philosophy 83 (3):307 - 330.

Parent, Ted. (2013) In the mental fiction, mental fictionalism is fictitious. The Monist 96 (4):605621.

Ramsey, William. (2021) What eliminative materialism isn't. Synthese. Published online 23 July 2021. https://doi.org/10.1007/s11229-021-03309-y

Ramsey, William. (ms) Defending representational realism.

Ramsey, William; Stich, Stephen P. \& Garon, J. (1991). Connectionism, eliminativism, and the future of folk psychology. In William Ramsey, Stephen P. Stich \& D. Rumelhart (eds.), Philosophical Perspectives. Lawrence Erlbaum. pp. 499-533.

Rosen, Gideon. (1990) Modal fictionalism. Mind 99 (395):327-354.

Schwitzgebel, Eric. (2019) "Belief", The Stanford Encyclopedia of Philosophy (Fall 2019

Edition), Edward N. Zalta (ed.), URL =

$<$ https://plato.stanford.edu/archives/fall2019/entries/belief/>.

Sprevak, Mark. (2013) Fictionalism about neural representations. The Monist 96 (4):539-560.

Steward, H. (1997) The ontology of mind: events, processes, and states. Oxford: Oxford University Press.

Stich, Stephen. (1983) From folk psychology to cognitive science: the case against belief. Cambridge, MA: MIT Press. 
Preprint September 2021: please cite published version

Drayson. Z. (forthcoming) 'What we talk about when we talk about mental states' in Tamas Demeter, Ted Parent and Adam Toon (eds.), Mental Fictionalism: Philosophical Explorations. Routledge.

Thomasson, Amie L. (2013) Fictionalism versus deflationism. Mind 122 (488):1023-1051.

Toon, Adam. (2016) Fictionalism and the folk. The Monist 99 (3):280-295.

Wallace, Meg. (2016) Saving mental fictionalism from cognitive collapse. Res Philosophica 93 (2):405-424.

Williamson, T. (2009) Replies to critics. In D. Pritchard and P. Greenough (eds.) Williamson on Knowledge. 279-384. Oxford: Oxford University Press.

Wright, Crispin. (1995) Can there be a rationally compelling argument for anti-realism about ordinary psychology? Philosophical Issues 6:197-221.

Yablo, Stephen. (2001) Go figure: a path through fictionalism. Midwest Studies in Philosophy 25 (1):72-102. 